\title{
Video Article \\ Rapid Point-of-Care Assay of Enoxaparin Anticoagulant Efficacy in Whole Blood
}

\author{
Mario A. Inchiosa Jr. ${ }^{1,2}$, Suryanarayana Pothula ${ }^{2}$, Keshar Kubal ${ }^{1,2}$, Vajubhai T. Sanchala ${ }^{2}$, Iris Navarro ${ }^{2}$ \\ ${ }^{1}$ Department of Pharmacology, New York Medical College \\ 2 Department of Anesthesiology, New York Medical College
}

Correspondence to: Mario A. Inchiosa Jr. at mario_inchiosa@nymc.edu

URL: https://www.jove.com/video/3852

DOI: doi:10.3791/3852

Keywords: Medicine, Issue 68, Immunology, Physiology, Pharmacology, low-molecular-weight-heparin, low-molecular-weight-heparin assay, LMWH point-of-care assay, anti-Factor-Xa activity, enoxaparin, heparinase, whole blood, assay

Date Published: 10/12/2012

Citation: Inchiosa Jr., M.A., Pothula, S., Kubal, K., Sanchala, V.T., Navarro, I. Rapid Point-of-Care Assay of Enoxaparin Anticoagulant Efficacy in Whole Blood. J. Vis. Exp. (68), e3852, doi:10.3791/3852 (2012).

\section{Abstract}

There is the need for a clinical assay to determine the extent to which a patient's blood is effectively anticoagulated by the low-molecularweight-heparin (LMWH), enoxaparin. There are also urgent clinical situations where it would be important if this could be determined rapidly. The present assay is designed to accomplish this. We only assayed human blood samples that were spiked with known concentrations of enoxaparin. The essential feature of the present assay is the quantification of the efficacy of enoxaparin in a patient's blood sample by degrading it to complete inactivity with heparinase. Two blood samples were drawn into Vacutainer tubes (Becton-Dickenson; Franklin Lakes, NJ) that were spiked with enoxaparin; one sample was digested with heparinase for $5 \mathrm{~min}$ at $37^{\circ} \mathrm{C}$, the other sample represented the patient's baseline anticoagulated status. The percent shortening of clotting time in the heparinase-treated sample, as compared to the baseline state, yielded the anticoagulant contribution of enoxaparin. We used the portable, battery operated Hemochron 801 apparatus for measurements of clotting times (International Technidyne Corp., Edison, NJ). The apparatus has 2 thermostatically controlled $\left(37^{\circ} \mathrm{C}\right)$ assay tube wells. We conducted the assays in two types of assay cartridges that are available from the manufacturer of the instrument. One cartridge was modified to increase its sensitivity. We removed the kaolin from the FTK-ACT cartridge by extensive rinsing with distilled water, leaving only the glass surface of the tube, and perhaps the detection magnet, as activators. We called this our minimally activated assay (MAA). The use of a minimally activated assay has been studied by us and others. ${ }^{2-4}$ The second cartridge that was studied was an activated partial thromboplastin time (aPTT) assay (A104). This was used as supplied from the manufacturer. The thermostated wells of the instrument were used for both the heparinase digestion and coagulation assays. The assay can be completed within $10 \mathrm{~min}$. The MAA assay showed robust changes in clotting time after heparinase digestion of enoxaparin over a typical clinical concentration range. At 0.2 anti-Xa I.U. of enoxaparin per ml of blood sample, heparinase digestion caused an average decrease of $9.8 \%(20.4 \mathrm{sec})$ in clotting time; at $1.0 \mathrm{I} . \mathrm{U}$. per ml of enoxaparin there was a $41.4 \%$ decrease (148.8 sec). This report only presents the experimental application of the assay; its value in a clinical setting must still be established.

\section{Video Link}

The video component of this article can be found at https://www.jove.com/video/3852/

Protocol

\section{Heparinase Reconstitution}

1. Lyophilized heparinase I is obtained commercially (Siemens, Newark Delaware, DadeHepzyme REF B4240-10) in vials containing $1 \mu \mathrm{gg}$ of the purified protein. The protein is dissolved in $0.25 \mathrm{ml}$ of saline $(0.9 \% \mathrm{NaCl})$.

\section{Collection of Blood Samples}

1. Two blood samples are drawn by vacuum into sodium citrate $(0.3 \mathrm{ml} 0.109 \mathrm{M} ; 3.2 \%)$ buffered Vacutainer tubes (Becton-Dickinson; Franklin Lakes, $\mathrm{NJ}$ ); the tubes are both pre-spiked with a known concentration of enoxaparin; the blood volume that is drawn is $2.7 \mathrm{ml}$. The total content is then $3.0 \mathrm{ml}$.

\section{Heparinase Digestion}

1. The entire contents of the heparinase vial that can be aspirated into a syringe (approximately $0.2 \mathrm{ml} ; 80 \%$ of the vial; $0.8 \mu \mathrm{g}$ of protein), is transferred to one Vacutainer tube; $0.2 \mathrm{ml}$ of saline $(0.9 \% \mathrm{NaCl})$ is added to the second tube, which serves as the baseline state before elimination of the enoxaparin effect. 
2. Both Vacutainer tubes are placed in the thermostated wells of the Hemochron apparatus for a period of 5 min. (The adequacy of a 5 min digestion time with heparinase was established in our previously published work. ${ }^{1}$ )

\section{Clotting Assays}

1. At the end of the heparinase incubation, $2.0 \mathrm{ml}$ of blood is transferred to the assay cartridge. In the case of the MAA tube, it is pre-filled with $0.1 \mathrm{ml}$ of $250 \mathrm{mM} \mathrm{CaCl}_{2}$ to initiate coagulation. The commercial aPTT assay cartridge (A104) is designed to initiate clotting in whole blood that has been drawn into Vacutainer tubes containing sodium citrate as anticoagulant.

2. The Hemochron apparatus signals the completion of blood coagulation and preserves the clotting times in seconds. The difference in clotting times between the heparinase-treated sample and the baseline sample, divided by the clotting time for the baseline sample, yields the percent decrease resulting from elimination of enoxaparin. As discussed below, strong linear correlations have been obtained for the relationship between percent decrease in clotting time and the concentration of enoxaparin in spiked samples of whole blood, as well as for the correlation with measured concentrations of enoxaparin by the chromgenic assay of anti-Xa activity. Anti-Xa assays of enoxaparin concentration were conducted with a commercial kit for a two-stage chromogenic assay (BIOPHEN; Aniara, Mason, $\mathrm{OH}$ ).

\section{Representative Results}

Figure 1 presents the results for the relationships between the percent decrease in clotting time following the elimination of enoxaparin with heparinase for a series of spiked concentrations of enoxaparin $(0.2,0.4$ and 1.0 anti-Xa IU per ml). Results are presented for both the MAA and aPTT assay cartridges. The measured concentrations of enoxaparin from chromogenic assay of anti-Xa activity are also included in the abscissa of each plot.

Figure 2 presents plots of the same data as percent decrease in clotting time vs chromogenic measure of anti-Xa activity.

Strong linear correlations, with high statistical significances, were found for all four relationships. 
Percent decrease in clotting time after heparinase digestion vs added concentrations of enoxaparin
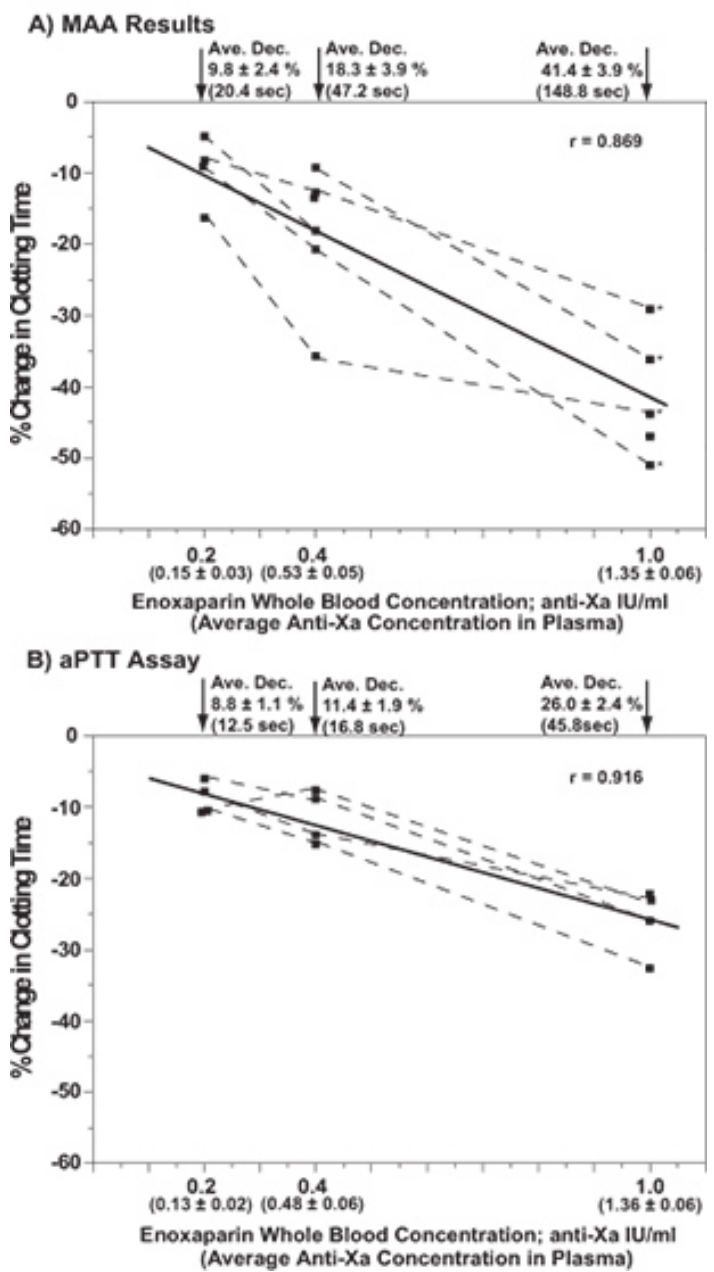

Figure 1. Point-of care determinations of enoxaparin contribution to clotting times of spiked whole blood based on percent change (shortening) of clotting time after incubation with heparinase. The spiked enoxaparin concentrations added to whole blood and the measured anti-Xa plasma concentrations (mean \pm S.E., in parentheses) are placed in the abscissa of each graph. All percent changes in clotting times are presented as means and S.E., together with the average shortening of clotting time in seconds. Data from the same patient are connected by dashed lines. The data for the four patients identified with asterisks in plot A (MAA results) are the same as the four patients in plot B (aPTT assays). All of the results represent single determinations. The Pearson correlation coefficients were $r=0.869\left(p=1.9 \times 10^{-5}\right)$ and $r=0.916\left(p=2.8 \times 10^{-5}\right)$ for the relationships with the MAA and aPTTassay, respectively. Reproduced with permission from Inchiosa et al. ${ }^{1}$ 


\section{Percent decrease in clotting time after heparinase digestion vs measured anti-Xa activity}
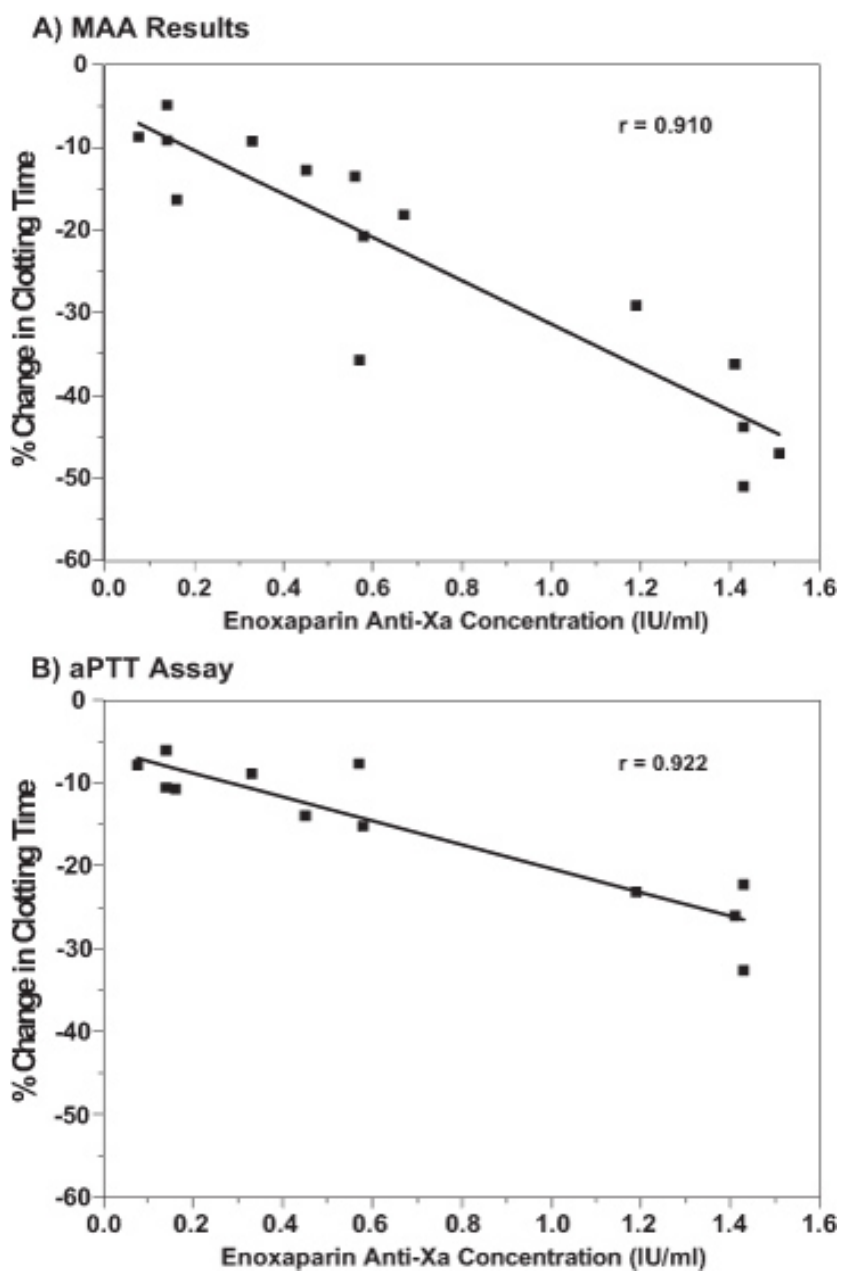

Figure 2. The results for the percent changes in clotting times in the point-of-care assays shown in Figures 1 A \& B are plotted against plasma anti-factor Xa concentrations. A, MAA results; B, aPTT assays. All of the results are from single clotting time assays and single determinations of anti-factor Xa concentrations. The Pearson correlation coefficients were $r=0.910\left(p=2.5 \times 10^{-6}\right)$ and $r=0.922\left(p=2.0 \times 10^{-5}\right)$ for the relationships with the MAA and aPTT assay, respectively Reproduced with permission from Inchiosa et al. ${ }^{1}$

\section{Discussion}

This assay of enoxaparin efficacy may serve as an important option to determine the relative safety of performing an invasive procedure that has an attendant risk of bleeding or development of a hematoma. This would be of particular importance when an epidural injection is being considered. The majority of guidelines recommend a waiting period of 12 hours between injection of enoxaparin and initiation of an invasive procedure. ${ }^{5}$ Renal impairment, obesity and pregnancy may influence the dosing requirements of enoxaparin. ${ }^{6,7}$ Since the assay can be completed within a 10-min period, it could also be used in a clinic or physician's office, where it would provide information on the adequacy of anticoagulation in patients who are at a risk of development of venous thromboembolism. Immediate dosage adjustments could be instituted, as needed.

The enoxaparin concentration in plasma can be measured by a chromogenic assay of the extent of inhibition of the coagulation factor, Xa. However, this only yields its concentration, not specifically its anticoagulant efficacy, which varies widely among individual patients. ${ }^{6-8}$

Our studies were carried out only with enoxaparin. However, it can be anticipated that the assay could be applied to any LMWH that is degraded by heparinase I. This is already known to be the case for dalteparin, nadroparin and tinzaparin. ${ }^{9-11}$ We designed the assay in relation to the features of the Hemochron clotting time instrument. The instrument is relatively inexpensive; also, the disposable blood collection tubes, heparinase ampoule, and assay cartridges to complete an analysis for one patient is approximately 15 U.S. dollars. Thus, it would be expected to be suitable to monitor anticoagulant status in various clinical settings. 


\section{Disclosures}

The authors have nothing to disclose.

\section{Acknowledgements}

The investigations were carried out solely with support from departmental and institutional resources. The coagulation apparatus (Hemochron 801 ) was loaned without obligation from the manufacturer. The assay cartridges were purchased at their retail costs. The introductory figure in the video was modified from Sanderink, et al. ${ }^{12}$ The second figure in the video (heparinase digestion time course) was reproduced with permission from Inchiosa et al. ${ }^{1}$

\section{References}

1. Inchiosa, M.A. Jr., Pothula, S., Kubal, K., Sanchala, V.T., \& Navarro, I. Toward development of a point-of-care assay of enoxaparin anticoagulant activity in whole blood. J. Thromb. Thrombolysis. 32, 47-53 DOI:10.1007/s11239-010-0546-5 (2011).

2. Despotis, G.J., Filos, K.S., Levine, V., Alsoufiev, A., \& Spitznagel, E. Aprotinin prolongs activated and nonactivated whole blood clotting time and potentiates the effect of heparin in vitro. Anesth. Analg. 82, 1126-1131 (1996).

3. Pothula. S, Inchiosa, M.A. Jr., Sanchala, V.T., Sarabu, M., \& Inchiosa, A.S. In vitro effect of protamine excess on blood coagulation assays. Anesth Analg. 96, SCA39 http://www.scahq.org/sca3/events/2003/annual/abstracts/A39.pdf. Accessed 26 August 2010, (2003).

4. Inchiosa, M. Jr, Pothula, S., Sanchala, V., \& Kubal, K. Detection of low plasma levels of low molecular weight heparin. Anesth Analg. 102, SCA10 http://test2.societyhq.com/sca3/events/2006/annual/SCA_2006_Abstracts.pdf\#page=16. Accessed 30 August 2010, (2006).

5. Gogarten, W. The influence of new antithrombotic drugs on regional anesthesia. Curr. Opin. Anaesthesiol. 19, 545-550 (2006).

6. Gouin-Thibault, I., Pautas, E., \& Siguret, V. Safety profile of different low-molecular weight heparins used at therapeutic dose. Drug Saf. 28, 333-349 (2005).

7. Bazinet, A., Almanric, K., Brunet, C., Turcotte, I., Martineau, J., Caron, S., Blais, N., \& Lalonde, L. Dosage of enoxaparin among obese and renal impairment patients. Thromb. Res. 116, 41-50 (2005).

8. El Rouby, S., Cohen, M., Gonzales, A., Hoppensteadt, D., Lee, T., Zucker, M.L., Khalid, K., LaDuca, F.M., \& Fareed, J. The use of a HEMOCHRON JR. HEMONOXTM point of care test in monitoring the anticoagulant effect of enoxaparin during interventional coronary procedures. J. Thromb. Thrombolysis. 21, 137-145 (2006).

9. Yang, V.C., Bernstein, H., Cooney, C.L., Kadam, J.C., \& Langer, R. Removal of the anticoagulant activities of the low molecular weight heparin fractions and fragments with flavobacterial heparinase. Thromb Res. 44, 599-610 (1986).

10. Maddineni, J., Walenga, J.M., Jeske, W.P., Hoppensteadt, D.A., Fareed, J., Wahi, R., \& Bick, R.L. Product individuality of commercially available low-molecular-weight heparins and their generic versions: therapeutic implications. Clinical and Applied Thrombosis/Hemostasis. 12, 267-276 (2006).

11. Wijnhoven, T.J., van de Westerlo, E.M., Smits, N.C., Lensen, J.F., Rops, A.L., van der Vlag, J., Berden, J.H., van den Heuvel, L.P., \& van Kuppevelt, T.H. Characterization of anticoagulant heparinoids by immunoprofiling. Glycoconj. J. 25, 177-185 (2008).

12. Sanderink, G-J. C.M., Guimart, C.G., Ozoux, M-L., Jariwala, N.U., Shukla, U.A., \& Boutouyrie, B.X. Pharmacokinetics and pharmacodynamics of the prophylactic dose of enoxaparin once daily over 4 days in patients with renal impairment. Thromb. Res. 105 225-231 (2002). 